\title{
Information flows and centrality among elite European newspapers
}

\begin{abstract}
Combining citations and network analysis, this study examines information flows between 10 European elite newspapers from 2000 to 2009 and identifies this network's most central actors, subgroups and structural features. At the same time, the paper contributes to the literature with an alternative and network approach to the study of the European public sphere. Results indicate that The Times and The Guardian are the most quoted by other foreign newspapers, while the top monitors of information are The Guardian and El Pais. A longitudinal analysis of structural network metrics indicate a less dense but more inclusive information exchange that can be interpreted as sign of a qualitative transformation of the European communication space in the direction of a horizontal integration.
\end{abstract}

\section{Keywords}

Information flows, Communication spaces, European elite newspapers, network centralities, European public sphere.

\section{Introduction: transnational information flows in Europe}

The study of information flows between media sources from different countries explores the dynamics underlying transnational communication spaces. There is no prevalent and accredited methodology for gathering data about transnational information flows, but there is a rather consolidated research literature that focuses on the interaction among European mass media within the context of study of a European public sphere (EPS). For example, Castells (1997) sees 
the emergent Euro-state not only as a political-economic zone but, by virtue of privileging its network character (the so-called Euro-matrix), also as a specific kind of communicative space.

In the current literature, there are three main aspects of the EPS and each involves a different theoretical angle and methodological approach: the attention of national media for EU politics, the Europeanization of national media and the communicative exchange between national public spheres.

The first approach focuses on the attention of national media for EU politics and issues. Typically, studies in this mode are based on content analysis methods that measure EPS by frequency of words that refer to EU affairs as proxy indicators of salience in European mass media, usually newspapers or television reporting (Gehards, 2002). The most common result in this approach is that European news is dwarfed in comparison with national and regional issues (Machill, Bellet et al., 2006). In terms of longitudinal trends, Meyer (2002) reports some increase in media attention towards European affairs during the 1990 s with some important distinctions on the nature of media reporting. Interestingly, several studies seem to indicate that there is rather little variation in terms of national media attention on European issues. The dominant themes being discussed and reported in national media seem to vary little across the EU (Sievert, 1998; Medrano, 2001; Meyer, 2002). The conclusion of this kind of research is that there is no EPS to speak of in a meaningful sense given the low salience of European issues in mass media, although the significance of the European dimension has increased slightly over the 1990 s.

The second approach focuses on the Europeanization of national media (Koopmans, 2004; Risse, 2003; Trenz, 2004). Studies of this kind are less pessimistic about the EPS. Concentrating on analysing media reporting on particular European issues, such as the debate over EU enlargement, the Lisbon Treaty, BSE, etc. (Koopmans and Erbe, 2004). On European issues, differences across Europe are not particularly large, demonstrating similar level of attention, and more importantly several European themes are framed in rather similar ways across 
national media, leading to similar interpretative schemes and structures of meaning (Eder, 1998, 2000; Eder and Kantner, 2000; Van de Steeg, 2000).

The third approach - the most relevant for this study - focuses on the communicative exchange between public spheres. Important within this approach is the notion of 'transnational public spheres' as formulated by Fraser (2007) in terms of discursive arenas and communicative circuits that 'overflow the bounds of nations and states' (Fraser, 2007: 7). Other applications of this idea of transnational public spheres include the 'Islamic public sphere' or the 'diasporic public spheres'. Fraser (2007) has argued that until recently notions of the public sphere have been conditioned by a Westphalian political imaginary; in other words, they are framed in terms of bounded communities with their own territorial state.

Approaches of this kind are not limited by the level of normativity of the definition of European public sphere they rely on ${ }^{1}$. As argued by Risse (2003:7-8), the traditional approach to the EPS so far has been an essentialist position. Rather than entities awaiting discovery, public spheres and communities of communication emerge through social practices and interactions. Europe is not an exception, it is unjustified to assume that European integration and institutions automatically lead to the emergence of a transnational public sphere. Bruggemann and Kleinenvon Konigslow (2009: 29) have argued in favour of differentiating between 'vertical' and 'horizontal' Europeanization. Vertical Europeanization denotes a process of paying closer attention to Brussels, while horizontal Europeanization stands for communicative linkages between different member states.

Koopsman and Erbe (2004) argue that there are two distinct forms of horizontal integration: a 'stronger form' in which 'actors from one country explicitly address, or refer to actors or policies in another member state' (Koopsman and Erbe, 2004, p.104); and a 'weaker horizontal integration', in which media cover debates in other member states. In order to investigate both forms of horizontal integration, the empirical focus is on communication flows and 'the relative density of public communication within and between spaces' (ibid.). A horizontal process of 
Europeanization can be studied in several ways. One theoretical and empirical possibility is in the form of information flows in terms of inter media observation and reference. Erbe (2005) distinguishes between four types of mechanism practiced by the media: 1) formal cooperation between media outlets; 2) inter-media observation, invisible to their audience and not explicit;

3) inter-media reference as news sources, in this case visible and explicit to their audiences; and 4) press reviews, in which media sources and personalities are acknowledged as political actors of their own and the quote each other's opinions (see Le Bart, 2004; Scherer and Vesper, 2004). Erbe (2005) argues that all four types of linkages should be empirically studied so as to better understand the ways in which the media arena is inter-linked.

This study presents a novel and complementary approach to the study of information flows across Europe, focusing on inter media references as news sources and combining citation and network analyses. A network analysis of European newspapers based on citations is an empirical attempt to highlight inter-linkages among European media and might contribute methodologically to the study of a 'weak' form of European horizontal integration. A similar attempt was carried out by Peters (2003) that focused on comparing the density of communication flows between within and outside the EU boundaries, which found that no significant difference was present. The aims of this study are: first, to map out the network of information flows among elite newspapers of several European countries and their longitudinal evolution; second, to contribute to the methodological debate on how to investigate a weaker form of horizontal integration in the European communicative space. In order to do so this study combines two methodologies - co-citations mapping and network analysis - in order to identify the most central newspapers and their roles in the information flows across five European countries (UK, France, Spain, Germany and Italy).

\section{Methodology}


Studying information flows requires a multi-method approach, using two different methodologies, one for data gathering and organization, and one for data analysis. The first methodology has been widely applied in bibliometric studies to study 'knowledge flows'. In this field of study, citations of patents and scientific articles are used as a means to identify knowledge flows across institutions and geographical areas such as regions or countries. Citations are considered as 'ties' and therefore as evidence of knowledge flows (Narin, Hamilton et al., 1997; Jaffe, Trajtenberg et al., 1993). Moreover, relational data obtained from citation analysis are used to measure the level of integration between actors, institutions or regions. The other methodology implemented in this study is social network analysis. According to Wasserman and Faust (1994), social network analysis is based on the assumption of the importance of relationships among interacting units. A social network perspective encompasses theories, models, and applications that are expressed in terms of relational concepts or processes. According to Scott (1992), social network analysis has emerged as a set of methods for the analysis of social structures, methods that are specifically geared towards an investigation of the relational aspects of these structures. One of the most important uses of network analysis is the identification of the 'most central' units in a network. Derived from social network analysis and inspiring this study is also the tradition of hyperlink analysis. Hyperlink structures are likely to be designed, sustained, or modified by website creators to reflect their communicative choices and agendas (Jackson, 1997; Pirolli and Card, 1999; Park, 2002).

Combining the methodology of citations' analysis and network analysis, this study analyses citations networks between elite newspapers across a 10 year period (2000-2009). Recent availability of electronic databases of newspapers articles allows fairly efficient co-citation queries and thus enables the building of citation matrices for newspapers. Data since 2000 were available for five countries - the UK, France, Spain, Germany and Italy - and for a total of 10 newspapers: The Guardian, The Observer, The Times, The Sunday Times, Le Monde, Le Figaro, 
El Pais, El Mundo, Sueddeutsche Zeitung ${ }^{2}$, Die Welt (and Welt am Sonntag), La Repubblica and Corriere della Sera.

The underlying rationale is that citations are the basis for an indicator of attribution of attention by the citer to the cited because they are an outcome of a process of monitoring, selecting and reporting. In this sense, citations are the web links of traditional texts. In the limited space available on a newspaper, a citation is a conscious choice that implies attention and monitoring of its source. One might argue that building matrices of co-citations is a relatively crude measure because the qualitative nature of a citation remains unspecified. In other words, what is not considered is the context and with what judgment a newspaper cites another one. However, this is a trade-off between an issue specific analysis but with limited scope and a 'bird's eye' view of the information flows, opting for a higher volume of ties between actors grasped and a wider range of data in terms of newspapers, countries and years.

Nevertheless, even though a citation is not qualified by a value judgment, it is still an outcome of a process of monitoring, selection and reporting that implies attention from the citer to the cited. An example is when a newspaper writes "At first sight, as Le Monde said, it looks rather like "a battle between two old men over an institution that is itself dissolving into ridicule...".(The Guardian 26/11/2003). A network based on this activity is a valuable object of study in the context of European horizontal integration of mass media.

Hence, the research questions addressed in this study are: Which are the most central newspapers and what are their network roles? What can the longitudinal evolution of this network tell us about the information exchange in Europe? More specifically, has the network's density and clustering increased or decreased in recent years?

\section{Data Collection and Corpus building}

Using citations as relational data enabled a network representation of information flows among the selected European newspapers to be conducted for each observation period. In order to be 
considered valid, a citation had to appear in an article's text. Press reviews were excluded; in other words, only citations within articles were counted. For every observation period, each newspaper's database was accessed to obtain citations of all other newspapers. Subsequently, data were organized in several adjacency matrices of co-citations.

Data were obtained mainly from the Lexis-Nexis electronic database of International National Newspaper Articles. Searching the Lexis-Nexis database was carried out using search strings 3 in the form of Boolean operators, built in filters and manual checking of the accuracy of results. Furthermore, in the collection of citations, The Times and Sunday Times, The Guardian and The Observer, and Die Welt and Welt am Sonntag were linearly aggregated for homogeneity respectively, in relation to the The Times and The Guardian. For the newspapers Repubblica, Corriere della Sera and Sueddeutsche Zeitung, data were obtained from newspapers' own digital databases because of the lack of coverage in Lexis Nexis for years prior 2007. The selected elite newspapers were: The Guardian, The Observer, The Times, The Sunday Times, Le Monde, Le Figaro, El Pais, El Mundo, Sueddeutsche Zeitung, Die Welt (and Welt am Sonntag), La Repubblica and Corriere della Sera. Three criteria were applied for selecting newspapers, with a particular emphasis on data availability and access that restrained this analysis to five countries and 10 newspapers: first, the availability and access of electronic databases of articles of the past 10 years; second, elite newspapers were selected since they are national newspapers of public record and with the highest circulation possible; and third, the study aimed to have for each country two newspapers of different political orientation so as to test politically-based transnational alliances.

The time frame analysed ranges from January 2000 to January 2010 for a total of 10 years. The corpus was organized into five observation periods, each containing all article citations for two years: $\mathrm{P}_{1}=2000$ and 2001; $\mathrm{P} 2=2002$ and 2003; $\mathrm{P}_{3}=2004$ and 2005; $\mathrm{P} 4=2006$ and 2007; $\mathrm{P}_{5}=2008$ and 2009. Data for El Mundo were not available in P1 and therefore the cumulative network was computed for $\mathrm{P}_{2}$ to $\mathrm{P}_{5}$ (2002-2009). The rationale behind having two years for 
each observation periods was to have adjacency matrices dense enough to enable meaningful network metrics computations and at the same time to retain sufficient detail for a longitudinal analysis.

\section{Matrix procedure}

Adjacency matrices were constituted for each corpus using citations' data obtained. Such matrix represents a graph with $n$ nodes as an $n$ by $n$ matrix, where the entry at $(i, j)$ is 1 if there is an

edge from node $i$ to node $j$, or zero if there is not. Weights of ties in each matrix represent the citation occurrences. In addition, separate matrices were created through grouping newspapers by political orientation and resulting in two matrices, a progressive and conservative one. The first group included The Guardian, The Observer, Le Monde, El Pais, Sueddeutsche Zeitung and La Repubblica; the second group contained The Times, The Sunday Times, Le Figaro, Die Welt and Corriere della Sera. The final step was to transform all matrices in dataset formats for software packages Ucinet and Agna in order to compute network metrics.

\section{Analysis}

In this study, several network metrics are interpreted as indicators of different roles in the information networks. Thus, the 'in degree centrality'4 of a newspaper is considered a measure of its 'importance' or 'prestige' because a newspaper with a higher in degree centrality develops many ties as many actors (other newspapers) seek direct ties to it. In the context of a citation matrix, to receive a tie means to be cited; hence in degree centrality is interpreted as an indicator of importance as source of information. Conversely, out degree centrality 5 stands for the number of ties (citations) that a newspaper establishes to other actors. Hence, out degree centrality is an indicator of a newspaper's information monitoring activity. 
Once in and out degree centralities are available, it is possible to obtain a 'determination degree' measure. The determination degree $^{6}$ of an actor is the difference between its reception and its emission degrees relative to the number of all other actors in the network. Thus, the determination degree allows newspapers to be classified as producers and consumers of information. In addition to degree based measures, this study includes 'information centrality',7 which is a non-directional network metric. According to Stephenson and Zelen (1989) there is no reason to believe that communication between a pair of nodes takes place only on the shortest paths linking them (or geodesic path, where geodesics are defined to be locally the shortest path between points in the space). Hence, information centrality is an indicator of how information might flow through many different paths, weighted by strength of tie and distance. Computing information centrality for each actor reveals how much an actor has control over the flow of information within a network. Hence, a higher information centrality value means that an actor plays the role of information 'gatekeeper'.

This study also analyses a number of structural network metrics, such as density, a centralization index, a factions' analysis and lambda set partitions. These indicators reveal structural features of the obtained networks. The weighted density of a network is the sum of all edged values divided by the number of all possible edges in that network. That is, with valued data, density is defined as the average strength of ties across all possible ties and refers to the degree of connectedness of a network. Network centralization index is an indicator of the degree of inequality or concentration in the distribution of flow centrality among actors of a network. It indicates the shape of the information flow among actors. Factions' analysis served the purpose of identifying subgroups within the overall network using a bottom-up approach - in other words, without superimposing any pre-selected grouping. Following a decomposition approach, on the other hand, a lambda set partitions analysis identifies a 'backbone network', one that if removed would cause the collapse of the network. 


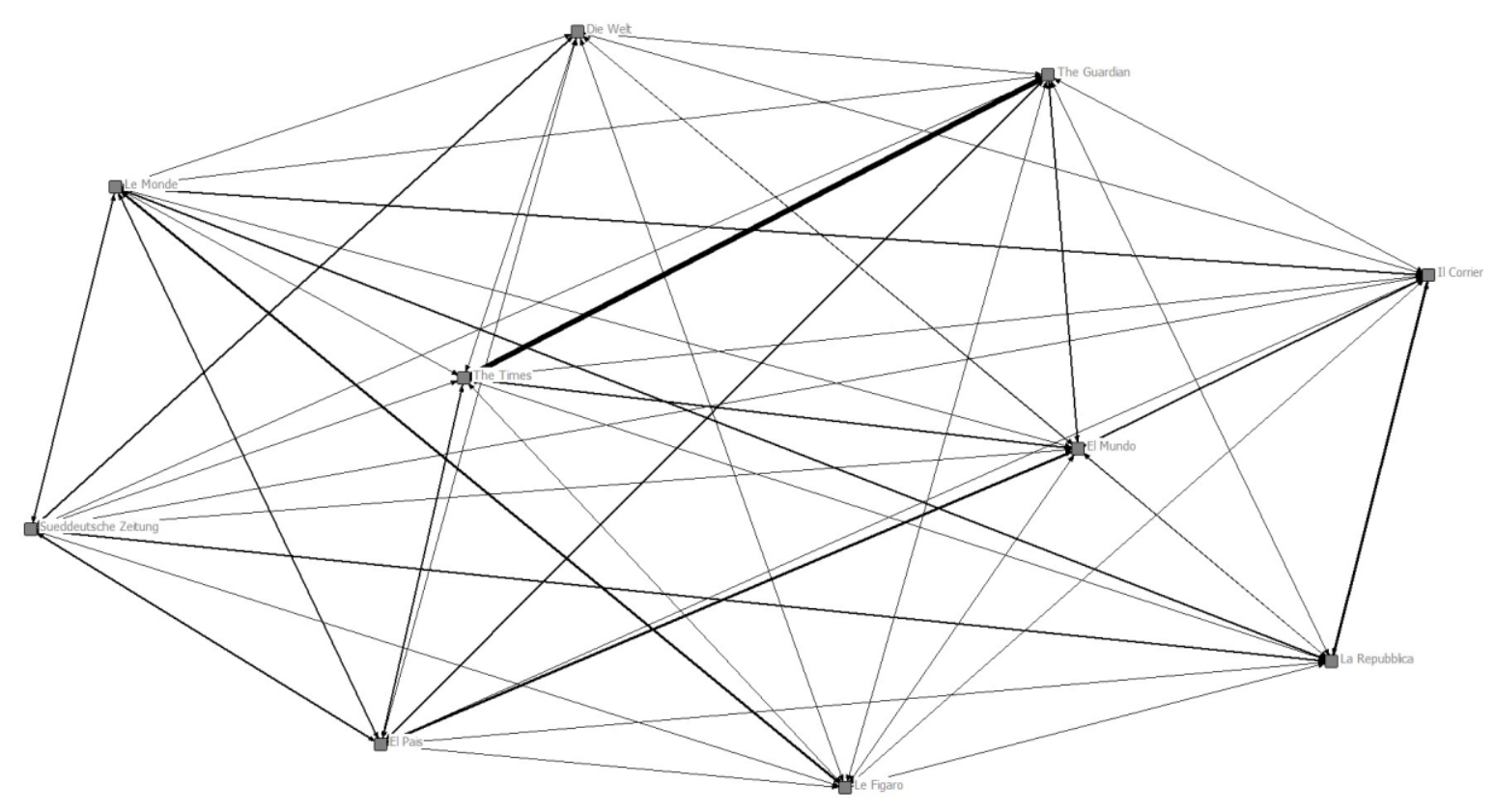

Figure 1 Visual representation of newspapers network, thickness of links stands for their weights.

\section{Cumulative Network}

This section presents an analysis conducted on a 'cumulative network' constituted by a linear aggregation of adjacency matrices of each observation period (Table1). Data for 'El Mundo' were not available for the years 2000-2001 and therefore the cumulative network was computed for P2 to P5 (2002-2009) or eight years of data (Figure 1). The same actor level network metrics were computed for both each observation period and the cumulative network. Specific to this cumulative network were faction and lambda sets partitions analyses.

\begin{tabular}{|l|r|r|r|r|r|r|r|r|r|r|}
\hline & $\begin{array}{l}\text { The } \\
\text { Guardian + } \\
\text { The } \\
\text { Observer }\end{array}$ & The Times & Le Monde & Le Figaro & El Pais & El Mundo & $\begin{array}{l}\text { Die Welt + } \\
\text { Welt am } \\
\text { Sonntag }\end{array}$ & $\begin{array}{l}\text { Sueddeutsc } \\
\text { he Zeitung }\end{array}$ & $\begin{array}{l}\text { La } \\
\text { Repubblica }\end{array}$ & $\begin{array}{l}\text { Corriere } \\
\text { della Sera }\end{array}$ \\
\hline $\begin{array}{l}\text { The } \\
\text { Guardian } \\
\begin{array}{l}\text { The } \\
\text { Observer }\end{array}\end{array}$ & 0 & 12137 & 674 & 353 & 329 & 219 & 141 & 24 & 340 & 377 \\
\hline The Times & 6322 & 0 & 554 & 398 & 196 & 155 & 74 & 14 & 376 & 377 \\
\hline Le Monde & 903 & 631 & 0 & 4113 & 1091 & 327 & 403 & 21 & 743 & 694 \\
\hline Le Figaro & 361 & 133 & 3050 & 0 & 385 & 170 & 359 & 47 & 267 & 418 \\
\hline El Pais & 1528 & 2037 & 2008 & 543 & 0 & 4306 & 134 & 278 & 889 & 672 \\
\hline
\end{tabular}




\begin{tabular}{|c|c|c|c|c|c|c|c|c|c|c|}
\hline El Mundo & 2528 & 2408 & 711 & 402 & 2379 & 0 & 130 & 15 & 271 & 1102 \\
\hline $\begin{array}{l}\text { Die Welt + } \\
\text { Welt am } \\
\text { Sonntag }\end{array}$ & 282 & 284 & 520 & 370 & 379 & 188 & 0 & 1887 & 403 & 360 \\
\hline $\begin{array}{l}\text { Sueddeutsc } \\
\text { he Zeitung }\end{array}$ & 464 & 473 & 1328 & 534 & 1143 & 446 & 501 & 0 & 1077 & 935 \\
\hline $\begin{array}{l}\text { La } \\
\text { Repubblica }\end{array}$ & 341 & 338 & 1500 & 363 & 656 & 270 & 200 & 191 & 0 & 3859 \\
\hline $\begin{array}{l}\text { Corriere } \\
\text { della Sera }\end{array}$ & 406 & 215 & 1245 & 462 & 187 & 460 & 177 & 52 & 2894 & 0 \\
\hline
\end{tabular}

Table 1 cumulative frequency of citations across newspapers.

The density of the cumulative network is of 942.8 citations. That is the average strength of ties among newspapers. The network centralization index (or the degree of concentration in the distribution of flow betweenness centralities among the actors) is fairly low (16.5\%). The network centralization index indicates an inclusive network, not concentrated in only a few actors, in which the information exchange is evenly distributed among all actors.

Table 2 Network metrics for the cumulative network: in-degree, out-degree, determination degree and information centrality

\begin{tabular}{|l|l|l|l|c|}
\hline Newspaper & $\begin{array}{l}\text { Weighted In- } \\
\text { degree }\end{array}$ & $\begin{array}{l}\text { Weighted Out- } \\
\text { degree }\end{array}$ & $\begin{array}{l}\text { Determination } \\
\text { Degree }\end{array}$ & $\begin{array}{l}\text { Information } \\
\text { centrality }\end{array}$ \\
\hline $\begin{array}{l}\text { The Guardian + The } \\
\text { Observer }\end{array}$ & 1459.4 & 1619.3 & -159.8 & 5978.9 \\
\hline $\begin{array}{l}\text { The Times + The Sunday } \\
\text { Times }\end{array}$ & 2072.8 & 940.6 & 1132.2 & 5994.1 \\
\hline Le Monde & 1287.7 & 989.5 & 298.2 & 6046.7 \\
\hline Le Figaro & 837.5 & 576.6 & 260.8 & 4583.4 \\
\hline El Pais & 749.4 & 1377.2 & -627.7 & 6142.9 \\
\hline El Mundo & 726.7 & 51104.0 & -377.2 & 5765.9 \\
\hline $\begin{array}{l}\text { Die Welt + Welt am } \\
\text { Sonntag }\end{array}$ & 235.4 & -283.7 & 3578.3 \\
\hline Sueddeutsche Zeitung & 275.4 & 766.7 & -491.3 & 5055.3 \\
\hline La Repubblica & 806.6 & 857.5 & -50.8 & 5051.08 \\
\hline Il Corriere della Sera & 977.1 & 657.5 & 279.5 & 5169.8 \\
\hline
\end{tabular}

Table 1 reports the most relevant network metrics values ${ }^{8}$ for each newspaper calculated from the cumulative adjacency matrix. The two most important newspapers (in-degree centrality) are the British newspapers The Times and The Guardian, with Le Monde following. The two top monitors of information (out-degree centrality) are the Guardian and El Pais.

Considering the overall activity of each actor, measured by determination degree, the picture is different. Determination degree can have both positive and negative values, in the context of 
this study a positive value indicates dominance (being quoted) and negative value consumption (quoting). 9 The biggest producer of information is The Times, followed by Le Monde; both are highly cited but cite below average other newspapers. The top consumers are El Pais and Sueddeutsche Zeitung, which are actors that cite very frequently but are not much cited by others.

Identifying actors with the highest information centrality values allows for the identification of the information gatekeepers, or those that have control over the flow of information within a network. Le Monde and El Pais are the newspapers with the highest overall values of information centrality and therefore they are regarded as the main information gatekeepers. Between being producers and consumers of information, their network positions allow them to reach and spread information across the network better than any other newspaper. There can be several determinants of this privileged position: successful strategic alliances with other newspapers, and complementarity with other news organizations, etc. The topic is interesting as a subject of a separate study but is outside this article's aims and scope.

\section{Sub-networks}

In this section I analyse groups of newspapers within the cumulative matrix applying two approaches, one bottom up and one top-down. First, a bottom-up strategy is adopted in two analyses, one that focuses on factions and another on lambda set partitions. The first technique recognizes factions emerging from the cumulative matrix. The second reveals the lambda set partitions. This considers whether there are certain connections in the network that, if removed, would result in a disconnected structure and therefore in the collapse of the network.

Subsequently, using a top down approach, the cumulative co-citation matrix was divided in two matrices defined by the political orientation of each newspaper, grouping them as conservative or progressive. 
Factions are groupings that have high density of ties within a group and low between groups. The results identified two significant factions as the optimal solution. The identification of factions within the matrix led to the following group assignments: group 1, Le Monde, El Mundo, Sueddeutsche Zeitung, La Repubblica and Il Corriere della Sera; group 2, The Guardian, The Times, Le Figaro, El Pais and Die Welt. Results show two factions that are different compared to groups that one would expect if political affiliation would be significant as a grouping variable. In other words, factions are established among newspapers according to other factors than similar political views.

Following a decomposition approach, a lambda set partitions analysis identifies sets of relationships that, if disconnected, would most greatly disrupt the flow of information among all actors. Results indicate that the 'backbone network' within the overall network is constituted by the ties between The Guardian, The Times, El Pais, El Mundo and Le Monde. Their network relationships are very dense and structurally important for the overall network, hence removing these nodes from the network would interrupt the overall flow of information. One explanation for this 'backbone network' of strong ties might be that these newspapers are complementary in terms of covering different language areas. The British newspapers are a reference in the Anglophone area, while El Pais pays much greater attention to Latin and South America. Le Monde has a long tradition of particular attention to Africa. The fact that the backbone network might capture the traditional newsgathering capability of newspapers and therefore the role of British, French and Spanish newspapers in different world areas accounts for the sheer volume of citations that the backbone's newspapers have. However, it does not account for the network centralities and roles so far discussed. For example, both El Pais and the British Guardian are also active overall monitors of other European newspapers. In addition, relationships between newspapers' emerging groups as shown in the faction analysis do not support only interpreting results only in terms of newsgathering capacities. Unless the citations are qualified by topic, it is impossible to have a complete picture of the reasons behind the citations patterns. Such 
refinement will be a challenge given the large number of articles. Further investigation is required on these newspapers and their market strategies so as to identify the reasons behind such strong ties.

From a different perspective, using top-down analysis, the cumulative adjacency matrix can be redesigned in two matrices, one including all the politically progressive newspapers and another with the conservative ones. Thus, the two networks obtained are datasets for further analysis. Considering the overall activity of progressive newspapers, in other words their determination degree, Le Monde and The Guardian are the most prominent actors as producers of information, while El Pais and Sueddeutsche Zeitung are the top passive actors. Le Monde and El Pais have the highest values in terms of information centrality that means an important role as 'gatekeepers' over the flow of information within a network. The weighted density $(d=$ 774.4) of the progressive network is higher compared to the conservative network $(d=432.1)$ meaning that the former is more connected and ties are stronger than in the latter. In the conservative network, the most important newspaper is The Times, while the biggest consumer of information is the Spanish El Mundo. The same two newspapers also have the top values of information centrality, and hence they are at the centre of information flows, although with different roles.

In conclusion, a bottom up approach to identifying sub groups in the network reveals two factions that are not organized according to political orientation. However, taking into consideration the progressive-conservative grouping, the progressive network is more cohesive than the conservative one, thus indicating a higher tendency to monitor and cite each other. The Guardian, The Times, El Pais, constitutes the most important sub network El Mundo and Le Monde, and they are at the core of the information flow of the overall network. 


\section{Longitudinal analysis}

The following step was to analyse adjacency matrices for each observation period. The same network metrics computed for the overall matrix were applied to define actor level and structural properties of each network. Hence, this section presents the results of a longitudinal analysis of in degree ${ }^{10}$ centrality, out degree centrality, ${ }^{11}$ determination degree, information centrality and network density.

Observation period P1 (2000-2001) was analysed first. The Times had the highest value of indegree centrality followed by Le Figaro and The Guardian. These are the newspapers that were cited most frequently by other newspapers and therefore are the most important and largest producers of information. Le Monde had the highest out degree followed by The Guardian and The Times and therefore they are the top monitors of information. Considering the overall communication activity of each actor and using as indicator their determination degree, the top producer of information was The London Times followed by Le Figaro, while the top consumer was Le Monde followed by Sueddeutsche Zeitung. P1's network is considered separately from the other observation periods' networks because data were not available for El Mundo, and therefore this network is structurally different (one less node and relative links) and not longitudinally comparable with the other obtained networks. The remaining observation periods are comparable because datasets are complete for all newspapers.

The data indicate a remarkable stability for the top newspapers in terms of importance. Across all remaining observation periods, The Times is the most important newspaper followed by The Guardian and Le Monde. Data on out-degrees values between 2002-2009 (P2-P5) show that in later years ( $\mathrm{P}_{4}$ and $\left.\mathrm{P}_{5}\right)$, The Guardian was the top monitor of information with the highest out-degree values while in P2 (2002-2003) Le Monde played this role. In the period in between ( $\mathrm{P}_{3}-\mathrm{P}_{4}$, 2004-2007), El Pais was also a top monitor of information. Out-degree centrality changed more than in degree across time. There is a prolonged decrease of Le Monde 
from $2002\left(\mathrm{P}_{2}\right)$ to $2009\left(\mathrm{P}_{5}\right)$ in terms of importance as a monitor of information. From 2002 to 2007, El Pais constantly became a more significant monitor of information, dropping slightly in the last period. In the last two periods instead, The Guardian and The Times increased their role as monitors. Again, there could be many reasons for such variance. For example, a decreased monitoring activity of a newspaper might be due to a larger focus on national news. This could be the case for Le Monde and Le Figaro, considering that in those years France witnessed a large number of important national events, including the presidential elections of 2007.
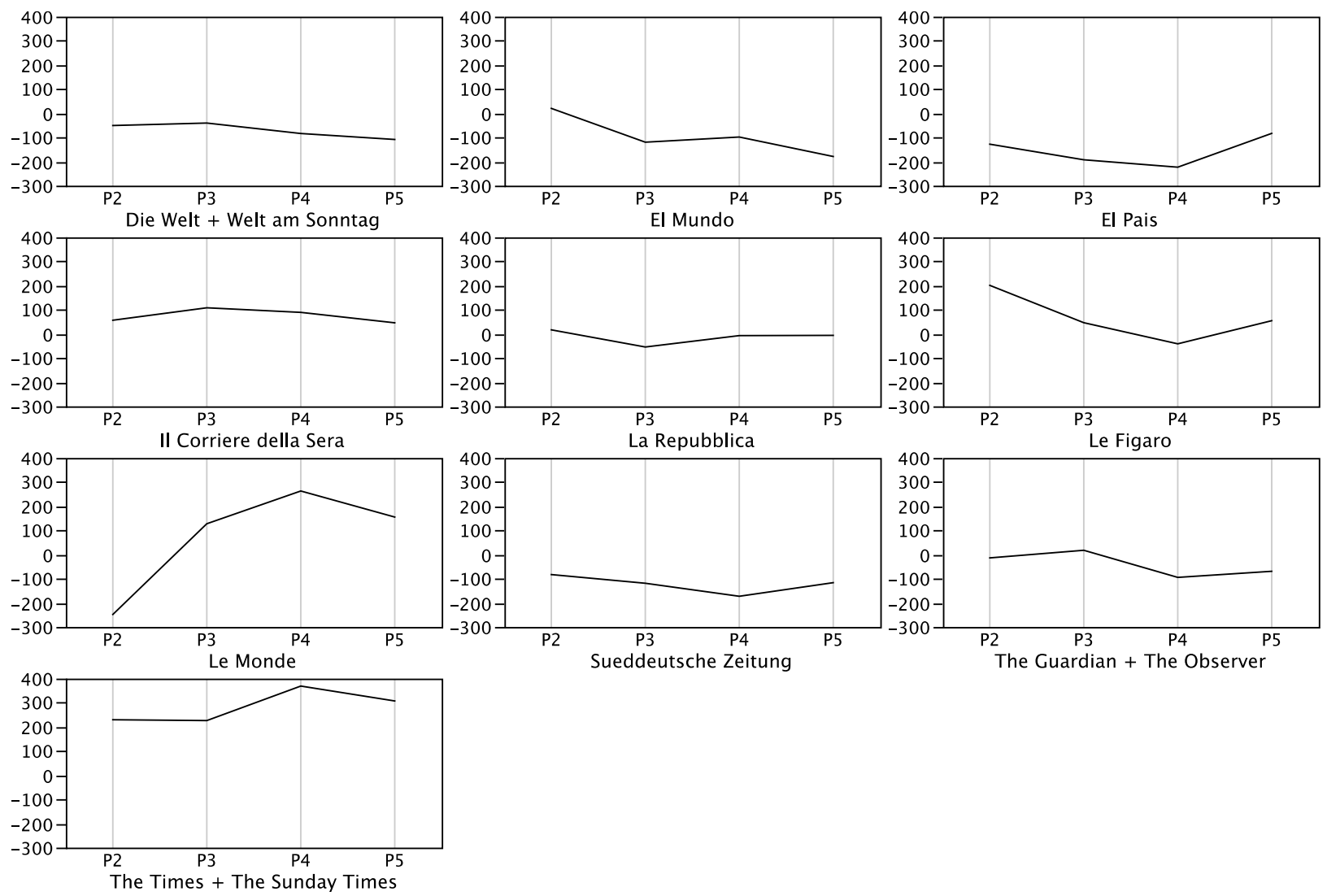

Figure 2 Parallel plots of longitudinal trends of determination degree values across observation periods and newspapers

Having obtained in degree and out degree values, the next step was to compute the determination degree of each actor to determine dominant and passive actors. Figure 2 reports longitudinal results for all 10 newspapers. Overall, The Times and Le Monde are highly 
dominant newspapers, although both had a slight decrease in the last period observed. El Pais and Le Figaro show an upward trend in recent years, while between the years 2002-2009 all other newspapers are remarkably stable.
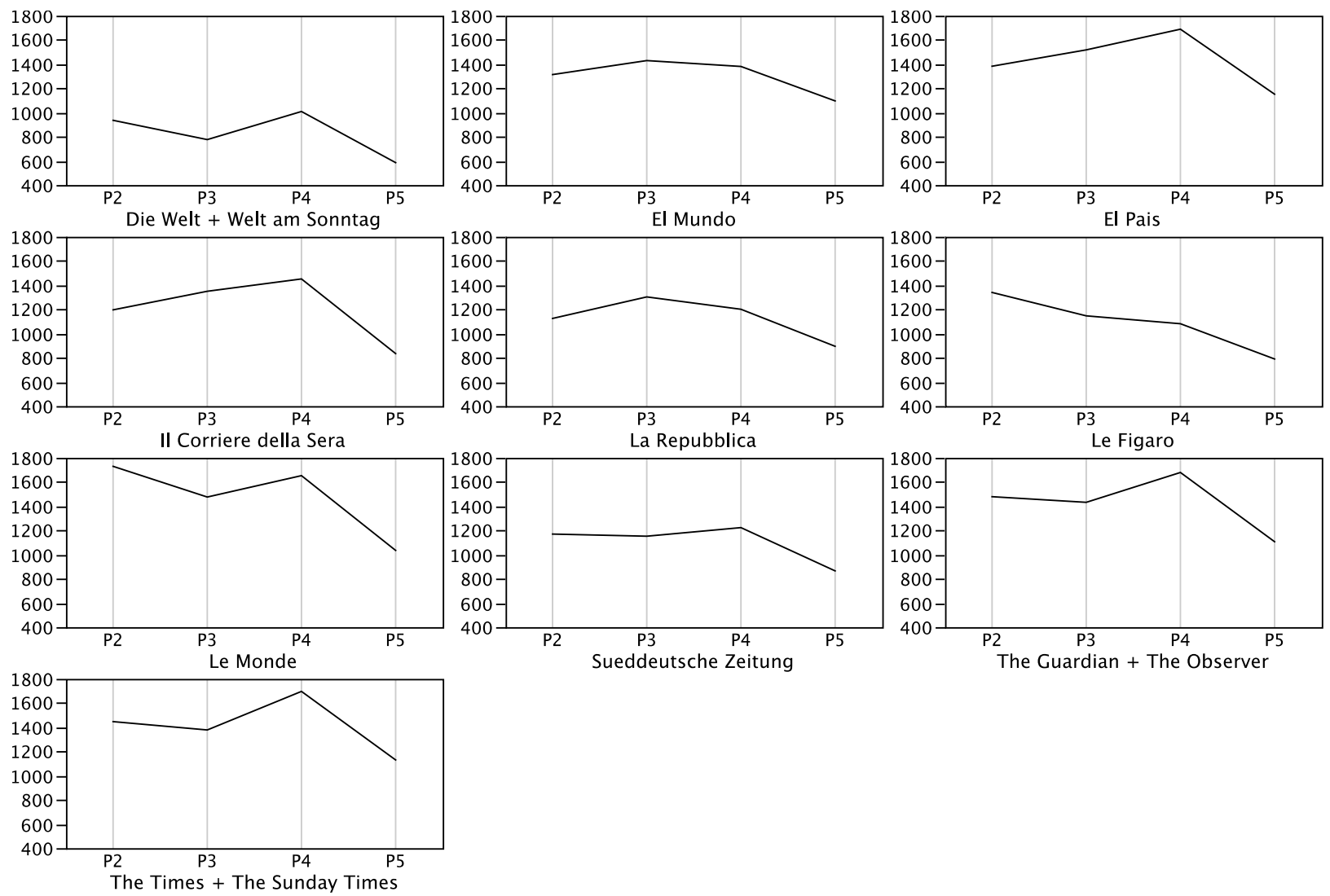

Figure 3 Parallel plots of longitudinal trends of information centrality across observation periods and newspapers

Lastly, information centrality was computed to have a not degree-based centrality measure and a non-directional network metric. In this case, an actor that has high information centrality is at the centre of information flow regardless of its direction (citing or being cited). In the case of P1, not directly comparable to all other observation periods, Le Monde, followed by The Guardian and The Times had the highest level of information centrality. Figure 3 reports longitudinal trends of information centralities values across remaining observation periods starting from $\mathrm{P}_{2}$ to $\mathrm{P}_{5}$. The general trend across each newspaper is of a diminished information 
centrality in the last period $\mathrm{P}_{5}$. The interpretation of this finding is that in later years the information flow is less clustered and this explains an overall decline in information centrality. This is evidence for a more even and widespread information exchange among European newspapers. An interpretation that is confirmed by another network metric: the network centralization index, discussed in the next section.

\section{Structural features}

Using valued data, network density is defined as the average strength of ties across all possible ties and is considered as the degree of connectedness of the newspapers' network of citations. Thus, it assumes the meaning of the degree of information exchange in the overall network. A higher or lower level of network density can be interpreted as a measure of more or less horizontal integration across European newspapers.

Network density was in $\mathrm{P}_{2}$ 242.5, $\mathrm{P}_{3}$ 227.3, $\mathrm{P}_{4} 248.5$ and $\mathrm{P}_{5}$ 224.4. The weighted density for the observed P1 was 229.9 but it is not comparable with the other periods, as mentioned previously. Differences across observation periods were statistically significant. ${ }^{12}$ Clearly the data available cover between the years 2000 and 2009 and comparable data before this time frame are not available. Comparing observation periods on their weighted densities, results indicate a lower density in the last observation period. The implication of this decrease in density of ties is less information exchange among the selected European newspapers. A constant increase of density would be evidence of an increasing intra-European information flow supporting the idea of a horizontal integration across European media. Density did not increase but the network centralization indicator is more supportive of a process of European horizontal integration. The network centralization is lower in the last years (P1, 22\%; P2, 29.7\%, $\left.\mathrm{P}_{3} ; 14.4 \% ; \mathrm{P}_{4}, 16.3 \% ; \mathrm{P}_{5}: 9.7 \%\right)$. This measure is complementary to network density and indicative of how inclusive or less concentrated a network is. In the last years, the data show a 
decrease in the network centralization index (NCI) value, indicating a more inclusive network than in previous years. NCI is an indicator of the quality of the information exchange and shows that information flows are less concentrated on few newspapers and more widespread across all actors. This is supported by the drop in information centrality for each actor in $\mathrm{P}_{5}$ showed previously.

\section{Conclusions}

This study has identified a network of information flows based on monitoring and references among several elite European newspapers, and it reveals their network roles, the structural feature of the network and the longitudinal evolution of both. The methodology applied for studying information flows can enrich the debate on the inter-media references as a proxy for a weaker form of horizontal integration among European media (Koopmans and Erbe, 2004). Results indicate that The Times and The Guardian are the most quoted by other newspapers. The top monitors of information are The Guardian and El Pais, closely followed by Le Monde. The Times is also the leading producer of information, followed by Le Monde; these are highly cited but cite below average other newspapers. The top consumers are El Pais and Sueddeutsche Zeitung. Two newspapers played the role of information gatekeepers, Le Monde and El Pais. A factions' analysis of the overall network identified two subgroups that suggest precise strategic alliances among newspapers and do not follow the political orientation of each newspapers. However, considering ties among progressive and conservative newspapers, the former subnetwork is denser than the latter.

Longitudinal results showed a considerable stability in the values of in, out and determination degree and therefore of associated network roles. Trends in information centrality values indicate a tendency to convergence in recent years and this suggests a decreased role of individual actors having the role of 'gatekeepers'. Network density is lower in 
recent years, indicating a less intense flow of information between European newspapers. However, network centralization index is also lower in these years, suggesting a more inclusive network and therefore a more evenly distributed information exchange among newspapers. Thus, network level data indicate a less dense but more balanced network of information flows among European newspapers that can be interpreted as a signal of a qualitative transformation of the European communicative exchange. This finding informs about the qualitative aspects of a horizontal integration, rather than only the quantitative aspects expressed by network density.

Monitoring levels of cohesiveness, integration and intensity of interactions in the information flows between European newspapers should be one of a set of indicators based on different methodologies applied to the study of the communication exchange and horizontal integration $\mathrm{n}$ Europe, as suggested by Erbe (2005), which should therefore including other types of intermedia linkage activities, for example press reviews. A useful follow up to this study would thus be to include other national newspapers from additional European countries and possibly more newspapers for each country, resulting in a more comprehensive network. However, limitations in retrieving newspapers articles from digital archives are still an obstacle. And, indeed, the limitation of this study consists in having data for five countries and 10 newspapers. Yet, as improvements in databases are frequent, the hopes are that it will be possible in the near future to include a wider range of actors and perform further analysis. The same methodology of this study can be applied to track initiators of a particular topic among European newspapers. It should be feasible to identify the most central newspapers across several European countries on a given issue and their role in longitudinal terms.

In conclusion, a network approach to studying the horizontal integration between European mass media outlets in terms of information flows is beneficial and complementary to the current content analysis and qualitative methodologies. This study presents an example of one dimension of the European communication transnational exchange that can be empirically 


\section{explored and can contribute to current methodological and theoretical debates on the European}

public sphere.

${ }^{1}$ Often the EPS is conceptualized as an idealized picture of homogenous national public sphere transferred to a panEuropean level. However, the prevailing view in communication research is that a pan-European public sphere independent of individual states does not exist and it is also regarded as relatively improbable that there will be a development towards it in the medium term (Gerhards, 2002: 142).

${ }^{2}$ The first choice as German leading newspaper was The Frankfurt Allegmaine Zeitung (FAZ). However this newspaper is not available on Lexis-Nexis and its digital archive is not freely accessible.

${ }^{3}$ For example, searches of citations of British The Times newspaper were designed to exclude results such as 'Financial Times', 'Bombay Times', 'New York Times' etc. An example of search string was CAPS (PLURAL (The Times)) NOT W/2 Financial OR Hindustan OR New York OR Irish OR Los Angeles OR Square OR Washington OR India OR Chicago etc.

${ }^{4}$ The in degree centrality was computed as:

$$
\text { Indegree }(i)=\frac{1}{g} \sum_{j-1}^{g} x_{j i}
$$

Where $g$ is the number of nodes and $x_{j i}$ are the socio-matrix elements.

${ }^{5}$ Out degree centrality applied formula is:

$$
\text { Outdegree }(i)=\frac{1}{g} \sum_{j-1}^{g} x_{i j}
$$

Where $g$ is the number of nodes and $x_{i j}$ are the socio-matrix elements.

${ }^{6}$ The formula for the weighted determination degree applied is :

$$
\operatorname{Det}(i)=\frac{1}{g-1} \sum_{j-1}^{g}\left(x_{j i}-x_{i j}\right)
$$

Where $i$ is the index of the current node and $x_{j i}$ are the edge values from the node $j$ to node $i$.

${ }^{7}$ Information centrality is computed following Stephenson and Zelen's (1989: 5.17) procedure, dividing each relative information index $C_{I}\left(n_{i}\right)$ by the total of all indices:

$$
C_{I}^{\prime}\left(n_{i}\right)=\frac{C_{I}\left(n_{i}\right)}{\sum i C_{I}\left(n_{i}\right)}
$$

${ }^{8}$ Most of these network metrics are correlated with each other. Out-degree centrality is highly correlated with information centrality $r=.787(8), \mathrm{p}<.01)$. On the other in-degree centrality is highly correlated with determination degree $r=.788(8), \mathrm{p}<.01)$ and also correlated with information centrality $r=.645(8), \mathrm{p}<.05)$. As mentioned above, information centrality is highly correlated with out-degree centrality and socio-metric status.

${ }^{9}$ The value is computed as the difference between an actor's reception and emission degree relative to the number of all other nodes or actors. In a different network, reception and emission of ties can assume the opposite meaning of this study. This is to say that reception might represent influence received while emission influence transmitted. In this case, a positive value of determination degree will be an indicator of passivity while a negative one of dominance.

${ }^{10}$ For a weighted network, the in degree of a node is the sum of all values corresponding to the edges incident to it divided by the number of all other nodes in the network.

${ }^{11}$ For a weighted network, the out degree of a node is the sum of all values corresponding to the edges incident from it divided by the number of all other nodes in the network. 
${ }^{12} \mathrm{~T}$-test for network densities compares the densities of two relations for the same set of actors, and calculates estimated standard errors to test differences by bootstrap methods. This is a test for a difference in the mean tie strengths of the two relations. Paired one way t-tests: P2-P3, t (8) = 0.2593, p <.001; P3-P4, t (8) $=0.3574, \mathrm{p}<.001$; P4-P5, $\mathrm{t}(8)=1.1072, \mathrm{p}<.05$. 


\section{References}

Bruggemann, Michael and Katharina Kleinen-von Konigslow (2009) 'Let's Talk about Europe': Why Europeanization Shows a Different Face in Different Newspapers. European Journal of Communication, 24(1): 27-48.

Eder, Klaus (2000) Zur Transformation nationalstaatlicher Offentlichkeit in Europa. Von der Sprachgemeinschaft zur issuespezifischen Kommunikationsgemeinschaft. Berliner Journal fur Soziologie, 10(2): 167-184.

Eder, Klaus and Cathleen Kantner (2000) ' Transnationale Resonanzstrukturen in Europa. Eine Kritik der Rede vom Offentlichkeitsdefixit', in M. Bach (ed) Die Europaisierung nationaler Gesellschaften. Sonderheft 40 der Kolner Zeitschrift fur Soziologie und Sozialpsychologie, pp. 306-331. Wiesbadem: Westdeutscher Verlag.

Erbe, J. (2005). What do the papers say? How press-reviews link national media arenas in Europe. Javnost-The Public, 12(2).

Fraser, Nancy (2007) Transnationalizing the Public Sphere: On the Legitimacy and Efficacy of Public Opinion in a Post-Westphalian World. Theory, Culture \& Society 24(4): 7-30.

Freeman, Linton C. (1979) Centrality in social networks: Conceptual clarification. Social Networks, 1: 215-239.

Gehards, Jurgen (2002) ‘ Das Offentlichkeitsdefixit der EU im Horizont normativer Offentlichkeitstheoriem', in H. Kaelble, M. Kirsch and A. Schmidt-Germig (eds) Transnational Offentlichkeiten und Identitaten im 20. Jahrhundert' Frankfurt/Main: Campus.

Jackson, Michele H. (1997) Assessing the structure of communication on the World Wide Web. Journal of Computer-Mediated Communication, 3(1):0. 
Jaffe, Adam B., Manuel Trajtenberg and Rebecca Henderson (1993) Geographic localization of knowledge spillovers as evidenced by patent citations. Quarterly Journal of Economics, 108: $577-598$.

Koopmans, Ruud (2004) 'Integrated Report "Analysis of Political Claims in European Print Media”, , Fifth Framework Programme of the European Commission, 'The Transformation of Political Mobilisation and Communication in European Public Spheres'; at: europub.wz-berlin.de

Koopmans, Ruud and Jessica Erbe (2004) Towards a European Public Sphere? Vertical and Horizontal Dimensions of Europeanised Political Communication. Innovation 17(2): 97-118.

Machill, Marcel, Markus Beller and Corinna Fischer (2006) Europe-Topics in Europe's Media: The Debate about the European Public Sphere: A Meta-Analysis of Media Content Analyses. European Journal of Communication 21(1): 57-88.

Meyer, Cristoph O. (2002) Europäische Öffentlichkeit als Kontrollsphäre: Die Europäische Kommission, die Medien und politische Verantwortlichkeit Vistas , Berlin.

Narin, Francis, Kimberly S. Hamilton and Dominic Olivastro (1997). The increasing linkage between US technology and public science. Research Policy, 26, 317-330.

Park, Han Woo (2002) Examining the determinants of who is hyperlinked to whom: A survey of Webmasters in Korea. First Monday, 7(11). Available at: http://pear.accc.uic.edu/htbin/cgiwrap/bin/ojs/index.php/fm/article/view/1005/926

Peters, B. (2005) 'Public Discourse, Identity, and the Problem of Democratic Legitimacy', in Erik O. Eriksen (ed.) Making the European Polity: Reflexive integration in the EU. London: Routledge 
Pirolli, Peter, Stuart K. Card (1999) Information foraging. Psychological Review, 106(4), 643675 .

Risse, Thomas (2003) 'An Emerging European Public Sphere? Theoretical Clarifications and Empirical Indicators', paper presented at the Annual Meeting of the European Union Studies Association (EUSA), Nashville, TN, 27-30 March. Available at: www.atasp.de/downloads/o30322_europe_public.pdfUniversity Press.

Schmoch, Ulrich (1997) Indicators and the relation between science and technology. Scientometrics, 38: 106-113.

Scott, John (1992), Social Network Analysis. Newbury Park CA: Sage.

Stephenson, K. and Zelen, M (1989) “Rethinking centrality: Methods and examples.” Social Networks 11, 1-37.

Trenz, Hans-Jorg (2004). Media Coverage on European Governance: Exploring the European Public Sphere in National Quality Newspapers. European Journal of Communication, 19(3), 291-319.

Van de Steeg, Marianne (2000) 'An analysis of the Dutch and Spanish newspaper debates on EU enlargement with central and European countries: suggestions for a Transnational Public sphere, in B. Baerns and J. Raupp (eds.) Transnational Communication in Europe, pp.61-87. Berlin:Vistas.

Wasserman, Stanley and Katherine Faust, (1994), Social Network Analysis. Cambridge: Cambridge. 